\title{
Re: A randomized controlled experimental study of the efficacy of platelet-rich plasma and hyaluronic acid for the prevention of adhesion formation in a rat uterine horn model
}

\author{
Emre Ata $^{1} \cdot$ Ali Yllmaz $^{2} \cdot$ Levent Tekin $^{1}$
}

Received: 8 April 2016/Accepted: 30 May 2016/Published online: 4 June 2016

(c) Springer-Verlag Berlin Heidelberg 2016

\section{Dear Editor,}

We read the recently published article by $\mathrm{Oz}$ et al. [1] with great interest. We would like to comment on an incorrect use about a technical issue. In the "Materials and Methods" section, the "1000 rpm for 15 min", "3000 rpm for $10 \mathrm{~min}$ " $0 \mathrm{~min}$ and "4000 rpm for $10 \mathrm{~min}$ " explanation was used wrongly while describing centrifuge method.

The "RPM" term has been "Revolutions (rotations) per minute" that is abbreviated as RPM, is the number of rotations around a stable axis in $1 \mathrm{~min}$ and is used as a measure of rotational speed of a mechanical component such as centrifuge device. Although RPM have been frequently used in the literature, it differs based on the rotor and the centrifuge tube use. Radius of the rotor in millimeters which is abbreviated as " $r$ ", stands for the distance from the top of a centrifuge tube to the bottom. G force (also referred to as the relative centrifugal force, $\mathrm{RCF}$ ) stands for how many times the gravity force is applied to your samples and it varies with the size of the rotor and RPM.

The function between $G$ force and RPM follows the equation: $\mathrm{G}$ force or $\mathrm{RCF}=(\mathrm{RPM} / 1000)^{2} \times 1.118 \times r$.
Two centrifuge machines with the same RPM but different radius do not apply the same $\mathrm{G}$ force on your samples. But the $\mathrm{G}$ is the constant centrifugal force applied on the sample which does not change with the rotor conditions. Although $\mathrm{G}$ is standard, RPM will not always represent the same force in different machines.

Consequently, it will be more accurate when the authors use G force instead of "runs"' in the materials and methods section.

\section{Compliance with ethical standards}

Conflict of interest No conflict of interest was declared by the authors.

\section{Reference}

1. Oz M, Cetinkaya N, Bas S, Korkmaz E, Ozgu E, Terzioglu GS, Buyukkagnici U, Akbay S, Caydere M, Gungor T (2016) A randomized controlled experimental study of the efficacy of platelet-rich plasma and hyaluronic acid for the prevention of adhesion formation in a rat uterine horn model. Arch Gynecol Obstet (Epub ahead of print)
Levent Tekin

leventtekin@yahoo.com

1 Department of Physical Medicine and Rehabilitation, GATA Haydarpaşa Training Hospital, İstanbul, Turkey

2 Department of Obstetric and Gynecology, GATA Haydarpaşa Training Hospital, İstanbul, Turkey 